\title{
Top Priority of Software Success Factors for Six Sigma Execution by a Fuzzy Hierarchical Process
}

\author{
Chandrakanth.G.Pujari ${ }^{1}$ and Dr.Seetharam. $\mathrm{K}^{2}$ \\ ${ }^{1}$ Associate Professor, Department of M.C.A, Dr.A.I.T, Bangalore, Karnataka, India \\ and Research Scholor Sathyabama University Chennai \\ ${ }^{2}$ Professor, CSE, R.G.I.T, R.T.Nagar, Bangalore, Karnataka, India \\ 1varuncp@rediffmail.com, 2amoghks@rediffmail.com
}

\begin{abstract}
Six-Sigma quality enhancement methodology has received important attention in various software development and service organizations. There have been some researches recognizing serious software success factors for Six-Sigma execution Within available resource compulsions, an immediate adoption of all sexious software success factors may not be possible. In order to be able to consolidate resources for some of the most important factors, top priority serious software success factors have to be determined. This will enable Six-Sigma practitioners and policy makers to anderstand the relative importance among the software success factors and develop impropement ideas for resource provision. The aim of this paper is to present fuzzy hierarchy process (FHP) based on methodology with the use of triangular fuzzy values for pair wise comporison scale to top priority serious success factors for Six-Sigma execution. The weights of success factors are determined by software experts including software managers, Six-sigma Green-Belts and Black-Belts from different multinational organizations in the software industry in India. This paper is an attempt to top priority to the serious softrare success factors of executing Six-Sigma methodology by using FHP approach.
\end{abstract}

Keywords: Sertous software success factors, Software criteria, Six-Sigma, Fuzzy logic, Fuzzy Hierarchy Process

\section{Introduction}

Six sigma as a quality management tool is a useful technique for achieving competitive advantage over rival organizations in the competitive environment of both software developing and service enterprises [1]. Six sigma may be named as a most powerful and comprehensive management tool which is necessary in order to bring changes in organization and also in making conformity with customer requirements [2]. Software quality management has been considered as an important strategy for achieving competitive advantage over rival industres [3]. Continuous improvement towards software performance excellence is the competitive edge for commercial companies to survive in highly competitive markets [4]. Among the various business improvement approaches available, the Six-Sigma approach has been recognized as one of the most effective methods. Many software quality initiatives such as total quality management, zero defects and statistical quality control has been used for many years, but Six-Sigma is a recent quality improvement initiative that has gained popularity and success in many software companies and even in service organizations across the world[5]. Software development performance evaluation is very complex and extensive related to many definite and indefinite factors [6]. In addition, software developers usually 
have different strategies and management approaches such as total software quality management; optimize production realization to accomplish their goals and targets [7]. Several performance measurement systems have been proposed ranging from balance scorecard to fuzzy models. However in literature there are few fuzzy logic methods with fuzzy integral on measuring software development performance by multi-dimensions. Furthermore, in many researches software development performance in a company has been compared with other companies, but in our research we compare manufacturing performance by means of shift and overtime in a medium size enterprise operating in Indian software industry. The main purpose of this research is to guide developers evaluating their own companies in fuzzy multi-criteria environment by the ways of working such as single resource, binary resource, triple resource and overtime.

This research is the first attempt to top priority the software critical success factors of implementing Six sigma methodology. The knowledge on the top priority of softvere crifical success factors of executing Six sigma will lead to better understanding of the operational and strategic management in the future. Moreover, this paper enables managers and $p$ actitioners to focus on some of the most important software critical suceess factors in successful execution of Six sigma.

\section{Literature Review}

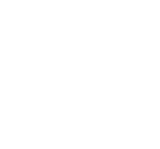

The Six sigma plan utilizes a very good disciplined approan The main features of the Six sigma approach are as follows:

- Links and sequence improvement software tools intoan overall approach Define-MeasureAnalyze-Improve-Control (DMAIC).

- More attention to bottom-line outputs and the sustaining of gains over time

- Collected human and process element for -mprovement using a Six sigma belt-based industries (Champion, Sirs sigma Black belt, and Six sigma Green belt) [7].

Six-Sigma to reduce procurement delay. Six-Sigma is applied using a software project management, under resource constraints. The project selection-decision, to maximize the financial results, s often challenging for a organization [7]. Software organizations can consider fou dimensions of the balanced score card, namely financial, software customer, internal business process and learning, and growth as the criteria for project selection [8]. SixSigma has the same content with that of the improved performance in both sales and revenue. Fuzzy assessments and multiple expert opinions can be considered. Human opinions are often in conflict because of group decision-making in a fuzzy environment. Different approaches to various aspects of decision problems with uncertain data have been published, and a significant amount of literature is available on fuzzy multiple criteria and decision making [9, $10]$.

In addition to the preceding performance measurement methods and models, there are someresearches based on fuzzy logic [14]. A model for software development experts and software managers to assess software development risks via two additive fuzzy logic approach for multi-criteria supplier measurement problem in order to obtain more effective outcomes [15]. How to deal with an organizational quantified performance aggregation process in a industry based on a fuzzy logic [16]. Using a fuzzy logic for assessing and deciding fourth party logistics operating models [17]. A quantitative model due to monitoring the overall performance of an enterprise based on a fuzzy logic aggregation operator and the model is applied to a organization [18]. 
In this study each linguistic parameter is defined by standardized trapezoidal fuzzy number [19]. A triangular fuzzy number should possess the basic features. In this paper fuzzy logic theory is deals with the extraction of the expected results from a different types of software data expressed in vague and imprecise terms [20]. Fuzzy logic treats to express vague information as certain distribution which can be executed for logical distribution reasoning, in terms of membership functions [21].

Fuzzy hierarchy Method not being able to overcome the deficiency of the fuzziness during decision making, This method have evolved the traditional into triangular fuzzy number of the fuzzy set theory into the pair-wise comparison matrix of the hierarchy process, for the purpose of solving not certain problems, which occur during the analysis of criteria and judgment process [22, 23]. In this method extent analysis method [24, 25] is applied to the evaluation the software critical success factors since the steps of this approach is similar to the traditional hierarchy process and relatively easier than the other fuzzy hierarchy process approaches [26, 27]. Standardized triangular fuzzy logic numbers are used to represent subjective pair-wise comparisons of Six sigma experts' verdicts. In this paper, the standardized triangular fuzzy logic conversion scale is used to convert sach linguistic scales into fuzzy logic scales in the investigation model as shown in Table 1 ,

Table 1. Fuzzy Scales with its Mempership Function

\begin{tabular}{|l|l|}
\hline Fuzzy Scales & Fuzzy Membership Function \\
\hline Equally important & \\
\hline Weakly important & $1,1,3$ \\
\hline Essentially important & $3,5,7$ \\
\hline Strongly important & $5,7,9$ \\
\hline Extremely important & $7,9,9$ \\
\hline
\end{tabular}

\section{Research Methodòlogy}

In this study, the fuzy matrix is constructed. In this research the standardized triangular fuzzy number is brough into the pair-wise comparison matrix of the fuzzy hierarchy process is described as follows:

Step 1: Problem Definition and Objective: The top priority of software serious success factors for Six sigma execution. This can be achieved by the effects of the software serious success factors on the software criteria.

Step 2: Build a Fuzzy Hierarchical Model: An effective method for analyzing complicated problem can be applied for constructing weights in hierarchical diagram of environmental effects at each stage. We constructed a hierarchical diagram for top priority of software serious success factors for Six-sigma execution as shown in the following Figure 1. 


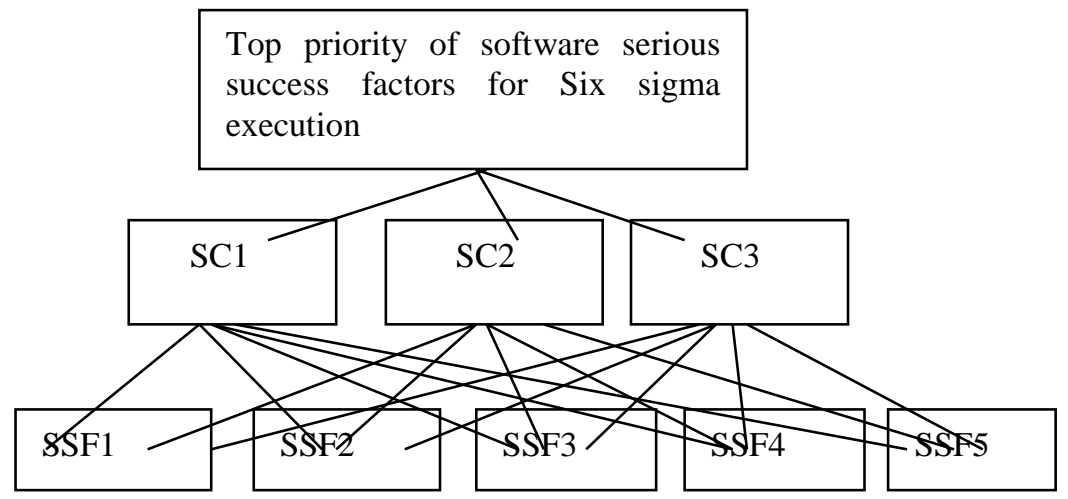

\section{Figure 1. The Hierarchical Diagram for Top Priority of Serious Success Factors for Six Sigma Execution}

The above hierarchical diagram depicts a three level fuzzy hierarchical model of top priority of software serious factors of executing Six sigma methodology, by/presenting the relationship between the software success criteria's and serious software success factors.

Software criteria's are as follows:

Where SC1 = software company financial status

SC2 = Customer Satisfaction about software

SC3 = Software Product improvements

Serious software success factors are as follows:

SSF1 = Software Top Management InvolvemenC

SSF2 = Infrastructure and Enyironment of the

\section{Software Company}

SSF3 = Software Training and Edacation

SSF4 = Six sigma to, Software business strategy

SSF5 = Six sigma to Custome

The level 1 of the fuzzy) hierarchical model expresses the aim of this research, which is top priority of software serious success factors for six sigma executions. The effects of software serious success factors on the software success criteria's. The level 2 expresses the three of software success criteria's. The last level features the software serious success factors.

Step 3: Construct Fuzzy Logic Matrix: We construct a fuzzy logic matrix for each of the last level elements, and then make the relationship of elements using the pair-wise comparison approach, the importance of relationship of the elements at same level w.r.t the element of their preceding level. In table 1. Taken linguistic elements based on every expert's judgments, the pair-wise comparison of five software serious success factors is more important than preceding level software success factors.

Step 4: Collective Opinions of Various Experts by using Geometric Mean: The informed judgments from a experts are collected through geometric mean is used for individual experts judgments. 


\section{Research Output}

As outputs of fuzzy evaluation of software success criteria and software serious success factors with respect to SC1. There are other two fuzzy evaluation of software success factors with respect to SC2 and SC3, which are the geometric progression mean values of the fuzzy logic judgment matrices are shown as follows in Table 2 and Table 3.

Table 2. Fuzzy Logic Comparison Matrix of Three Software Criteria with Respect to the Aim

\begin{tabular}{|l|c|c|c|}
\hline & SC1 & SC2 & SC3 \\
\hline SC1 & $1,1,1$ & $0.425,0.667,0.96$ & $0.521,0.72,1.581$ \\
\hline SC2 & $1.05,1.49,2.39$ & $1,1,1$ & $1.25,1,85,2.52$ \\
\hline SC3 & $0.64,1.45,2.02$ & $0.40,0.56,0.82$ & $1,1,1$ \\
\hline
\end{tabular}

Table 3. Fuzzy Logic Comparison Matrix of Softyare Serious Success Factors with Respect to SC1

\begin{tabular}{|c|c|c|c|c|c|}
\hline & SSF1 & \multicolumn{1}{|c|}{ SSF2 } & SSF3 & SSF4 & \multicolumn{1}{l|}{ SSF5 } \\
\hline SSF1 & $1,1,1$ & $0.9,1.43 .2$ & $0,1.2,2.6$ & $0.9,1.8,3.4$ & $0.4,0.7,1.3$ \\
\hline SSF2 & $0.3,0.7,1.2$ & 1,1 & $0.9,1.2,2.7$ & $0.4,0.5,1.2$ & $0.2,0.2,0.4$ \\
\hline SSF3 & $0.9,1.2,0.3$ & $0.4,0.8,1.1$ & $1,1,1$ & $0.4,0.7,1.4$ & $0.4,0.7,1.4$ \\
\hline SSF4 & $0.3,0.5,1.1$ & $0.9,1,9,2.5$ & $0.7,1.4,2.4$ & $1,1,1$ & $0.4,0.6,1.2$ \\
\hline SSF5 & $08,1.5,2.5$ & $2.6,4.5,6$ & $0.7,1.4,2.4$ & $0.8,1.7,2.5$ & $1,1,1$ \\
\hline
\end{tabular}

Here we calculate triangular fuzzy number values of three software criteria's by using the fuzzy logic evaluation values as shown in above Table 2.

Now we calculate Triangular fuzzy logic number values of software criteria are as follows: $\mathrm{S} 1^{(\mathrm{SC} 1)}=(1.946,2.38,3.541)\left(*(7.286,9.73,13.291)^{-1}\right.$

$$
(1.946,2.38,3.541)(*)(1 / 13.291,1 / 9.73,1 / 7.286)
$$

$=(0.146,0.245,0.486)$

$$
\begin{aligned}
\mathrm{S} 2^{(\mathrm{SC} 2)} & =(3.3,4.34,5.91)(*)(7.286,9.73,13.291)^{-1} \\
& =(3.3,4.34,5.91)(*)(1 / 13.291,1 / 9.73,1 / 7.286) \\
& =(0.248,0.445,0.811) \\
\mathrm{S} 3^{(\mathrm{SC} 3)} & =(2.04,3.01,3.84)(*)(7.29,9.73,13.29)^{-1}
\end{aligned}
$$




$$
\begin{aligned}
& =(2.04,3.01,3.84)(*)(1 / 13.29,1 / 9.73,1 / 7.29) \\
& =(0.153,0.309,0.526)
\end{aligned}
$$

Now we calculate the degree of probability of software criteria as follows:

$$
\begin{aligned}
& \mathrm{D}\left(\mathrm{S} 1^{(\mathrm{SC} 1)}>=\mathrm{S} 2^{(\mathrm{SC} 2)}\right) \\
& =(0.248-0.486) /(0.245-0.486)-(0.445-0.248) \\
& =0.543 \\
& \mathrm{D}\left(\mathrm{S} 1^{(\mathrm{SC} 1)}>=\mathrm{S} 3^{(\mathrm{SC} 3)}\right) \\
& =(0.153-0.486) /(0.245-0.486)-(0.309-0.153) \\
& =.838 \\
& \left.\mathrm{D}\left(\mathrm{S}^{(\mathrm{SC} 2)}>=\mathrm{S} 1^{(\mathrm{SC} 1)}\right)=1 \quad \text { (because } 0.445>0.245\right) \\
& \left.\mathrm{D}\left(\mathrm{S}^{(\mathrm{SC} 2)}>=\mathrm{S} 3^{(\mathrm{SC} 3)}\right)=1 \quad \text { (because } 0.445>0.309\right) \\
& \left.\mathrm{D}\left(\mathrm{S}^{(\mathrm{SC} 3)}>=\mathrm{S} 1^{(\mathrm{SCl})}\right)=1 \quad \text { (because } 0.309>=0.245\right) \\
& \mathrm{D}\left(\mathrm{S}^{(\mathrm{SC} 3)}>=\mathrm{S} 2^{(\mathrm{SC} 2)}\right)=(0.248-0.526) /\{(0.309-0.526)-(0.4450 .248)\} \\
& =0.67
\end{aligned}
$$

The weight vector as

$\mathrm{W}^{-}=(0.543,1,0.67)^{\mathrm{T}}$

After normalized weight vector as

$\mathrm{W}=(0.245,0.445,0.309)^{\mathrm{T}}$

Now we compute of veights of the software serious success factors with respect to the assessing software suceess eriteria's will not be given in this article because they are same calculation as above the overall weight of each software success factors is computed by multiplying its prionity weight with the three s/w criteria relative weights. We repeat the procedure of the local and overall weights for all levels in fuzzy hierarchy. The same procedure can apply for remaining data. Finally the outputs of top priority for software serious success factors are shown in Table 4.

In (ab)e 4, we shown the weights of software serious success factors related to three software success criteria and also shown average weight and top priority ranking of each software serious success factors. According to experts' judgments viewpoint through fuzzy hierarchical process approach, Six sigma to customer plays an important role in execution of Six sigma. Next important factor is software top management involvement, while software training and education is the least important. Now we conclude that customer satisfaction is most important. 
Table 4. Software Success Factor Weight Score and Average Weight Score of Software Serious Success Factors and their Top Priority Ranking. Brackets ( ) Denote the Weight of Each Software Criterion

\begin{tabular}{|c|c|c|c|c|c|}
\hline \multirow{2}{*}{$\begin{array}{c}\text { Software } \\
\text { Serious success } \\
\text { factor }\end{array}$} & \multicolumn{3}{|c|}{ Software criteria weight score } & $\begin{array}{c}\text { Average } \\
\text { weight score }\end{array}$ & $\begin{array}{c}\text { Top } \\
\text { Priority } \\
\text { Rank }\end{array}$ \\
\cline { 2 - 5 } & $\begin{array}{l}\text { SC1 } \\
\mathbf{( 0 . 2 4 5 )}\end{array}$ & $\begin{array}{l}\text { SC2 } \\
\mathbf{( 0 . 4 4 5 )}\end{array}$ & $\begin{array}{l}\mathbf{S C 3} \\
\mathbf{0 . 3 0 9}\end{array}$ & & \\
\hline SSF1 & 0.24 & 0.23 & 0.23 & 0.23333 & II \\
\hline SSF2 & 0.15 & 0.17 & 0.20 & 0.17333 & IV \\
\hline SSF3 & 0.15 & 0.10 & 0.14 & 0.13333 & I \\
\hline SSF4 & 0.21 & 0.19 & 0.25 & 0.21666 & III \\
\hline SSF5 & 0.30 & 0.26 & 0.23 & 0.26333 & I \\
\hline
\end{tabular}

\section{Summary and Conclusions}

This article studies the top priority of the software sen success factors in six sigma executions by using a fuzzy hierarchy process approach, which is applied to the software industry in India, and this article is demonstrate efficiency of the proposed approach. From literature review, 3 main software criteria and 5-50itware serious success factors are evaluated and used in this study. The top priority of the software serious success factors is very much necessary because it is infeasible to devote their efforts to all software serious success factors.

In promoting the success of executing Six sigma, professionals and management team required to devote their elforts to some software serious success factors that have the highest ranking such as the linking Six sigma to customer, and software top management involvement. In the beginning of executing the Six sigma, professionals and software top management tean should focus their efforts on the software serious success factor that has the highest ranking and gadually attend to the rest of the factors which have running ranking afterwards.

For the software criteria of executing six sigma methodologies, they required to focus on customer satisfaction as the first ranking. The ranking of software serious success factors enables professionals and policy makers to understand the relative importance among the software factors and software development an improvement strategy for an industries resource provision.

For research limitations, the proposed methodology is examined, from 3 software industries which is the limitation of this article. The strong point of the methodology can be examined by conducting several empirical researches in software industry and comparing the outputs with other industries or other existing methodologies.

Further researches may include sensitivity analysis of the outputs of this research in order to determine the influence of these coefficients on the final output. This methodology can applied to different companies with more serious factors. 


\section{Acknowledgements}

The authors wish to express their gratitude to Dr.AIT Management for all supports. We also thank for software practitioners who gave their experiences and time generously.

\section{References}

[1] R. Banuelas, C. Tennant, I. Tuersly and S. Tang, "Selection of Six sigma projects in UK", The TQM Magazine, vol. 18 no. 5, (2006), pp. 514-27.

[2] P. Nonthaleerak and L. Hendry, "Exploring The Six sigma Phenomenon Using Multiple Case Study Evidence", International Journal of Operations and Production Management, vol. 28, no. 3, (2008), pp. 279303.

[3] R. Kalamdani and F. Khalaf, "Application of Design for Six sigma to Manufacturing Process Design at Ford PTO”, International Journal of Product Development, vol. 3, (2006), pp. 369-387.

[4] F.W. Breygogle III, "Implementing Six sigma smarter Solution Using Statistical Methods" New York: Wiley, (1999).

[5] R. D. Snee and W.F. Rodenbaugh, "The Project Selection Process”, Quality Progress, vol. 35, no. 9, (2002), pp. $78-80$.

[6] D. G. Mark, “Six sigma Program Success Factors”, Six Sigma Foran Magazines, vol 1 (2001), pp. 36-45.

[7] C. T. Su, T. L. Chiang and K. Chiao, "Optimizing the IC Delamination Quality via Six sigma Approach", IEEE Transaction on Electronics Packaging Manufacturing, vol 28, (2005), pp. 241- 248.

[8] F. T. Anbari, "Six sigma method and its applications in project management", Proceedings of the Project Management Institute Annual Seminar and Symposium, (2002): San Antonio Texas.

[9] W. E. Deming, "Out of crisis ( $2^{\text {nd }}$ edition.)", Cambridger MA: MIT Press, (1986).

[10] G. Eckes, "Six-Sigma execution", New York, (2006); McOraw-Hill.

[11] B. Klefsjo, H. Wiklund and R. L. Edgeman, "Six-Sigma seen as a methodology for Total Quality Management", Measuring Business Excellence, vol.5, (2001), pp.31-35.

[12] D. Ritter, "A tool for improvement using the Báldrige critera", National Productivity Review, vol. 12, (1993), pp.167-182.

[13] P. Przekop, "Six-Sigma for busines ex cellence", (2006); New York: McGraw-Hill.

[14] T. Wang and Y. Chen, "Applying fuzzy linguistic preference relations to the improvement of consistency of fuzzy AHP”, Information Sciences, vol. 178, no. 19, (2008), pp. 3755-3765.

[15] V. Belton and T. J. Stewart, "Multiple Criteria_Decision Analysis", An Integrated Approach, Kluwer Academic Publisher, USA, (2002).

[16] A. I. Olcer and A. Y॰ Odabas1, "A New Fuzzy Multiple Attribute Group Decision Making Methodology and its Application to Propulsion/ Manoeuvring System Selection Problem", European Journal of Operation Research, vol. 166, (2005), pp. 93-14.

[17] J. Wang and X Lin, A Fuzzy Multicriteria Group Decision Making Approach to Select Configuration Items for Softwafe Development", Fuzzy Sets and Systems, vol. 134, (2003), pp. 343-363.

[18] Z. S. Xu and J. Chen, "An Interactive Method for Fuzzy Multiple Attribute Group Decision Making Information Sciences", vol. 177, (2007), pp. 248-263.

[19] I. S. Chang, Y. Tasuhiro and T. Tozawa, "An efficient Approach for Large Scale Project Planning Based on Fuzzy Delphi Method" Fuzzy Sets and Systems, vol. 76, (1995), pp. 277-288.

[20]C. Waxer, "Six sigma Costs and Savings: The Financial Benefit of Implementing Six sigma At Your Company can Be Significant Available at: www.isixsigma.com/library/content/c020729a.asp", (2007).

[21] D. Lynch and B. Soloy, "Improving the Effectiveness of Six sigma Project Champions", ASQ's Six sigma Conference (2003).

[22] H. De Koning and J. De Mast, "A Rational Reconstruction of Six sigma's Break through Cookbook", Anternational Journal of Quality and Reliability Management, vol. 23, no. 7, (2006), pp. 766-787.

[23] D. Goldstein, "Six sigma Program Success Factors", Six sigma Forum Magazine, vol. 1, no. 1, (2005).

[24] J. P. Zimmerman and J. Weiss, "Six sigma's seven deadly sins", vol. 44, no. 1, (2001), pp. 62-66.

[25] Y. H. Kwak and F. T. Anbari, "Benefits, obstacles and future of Six sigma", Technovation: The International Journal of Technological Innovation, Entrepreneurship and Technology Management, vol. 26, no. 5-6, (2004), pp.708-715.

[26] S. L. Chang, R. C. Wang and S.Y. Wang, "Applying fuzzy linguistic quantifier to select supply chain partners at different phases of product life cycle, International Journal of Production Economics, vol. 100, (2006), pp. 348-359.

[27] C. Tsung-Han and W. Ten-Chin, "Using the fuzzy multi-criteria decision making approach for measuring possibility of successful knowledge management", Information Sciences, vol. 179, (2009), pp. 355-370. 


\section{Authors}

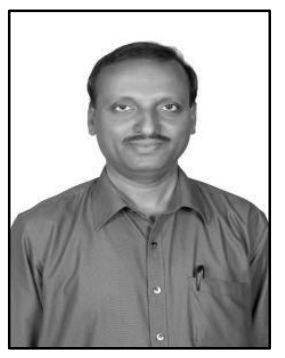

Chandrakanth G Pujari, he is working as an Associate Professor, Department of Computer Science and Applications, Dr. Ambedkar Institute of Technology Bangalore, India. He completed his B.Sc in 1991, M.C.A in 1995 from Gulbarga University and M.Tech in Computer Science and Engineering in 2012 from Mysore University. Pursuing Ph.D from Sathyabama University Chennai. He has over 20 National and International publications in Journal and Conference Proceedings. He is a life member of ISSS and ISTE. His research areas include Software Engineering, Six Sigma, Fuzzy Logic, Software Metrics, Software Reliability, Software Quality, Image Processing and Social Networks.

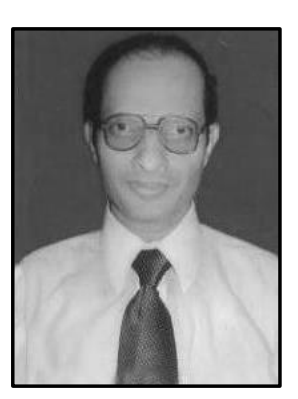

Seetharam. K, has received BE degree from Bangalore University, $\mathrm{M}-\mathrm{Tech}$ and $\mathrm{PhD}$ Degree both from IIT Bombay. He has worked in various Engineering Colleges at varioas levels. He has worked as system analyst in TCS Bangalore based company providing software solutions worldwide, He has published many papers. Currently working as professor and head of Department in Electrical Engineering in Rajiv Gandhi Institute of technology Bangalore Hits area of interest is software engineering and soft computing.

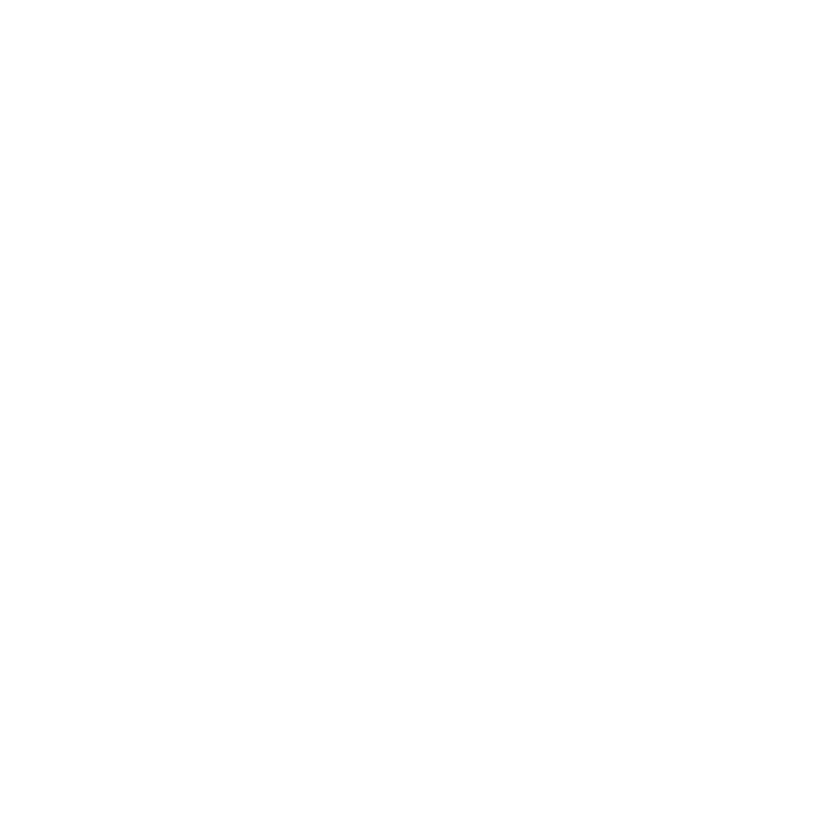


International Journal of Multimedia and Ubiquitous Engineering Vol. 9, No. 11 (2014)

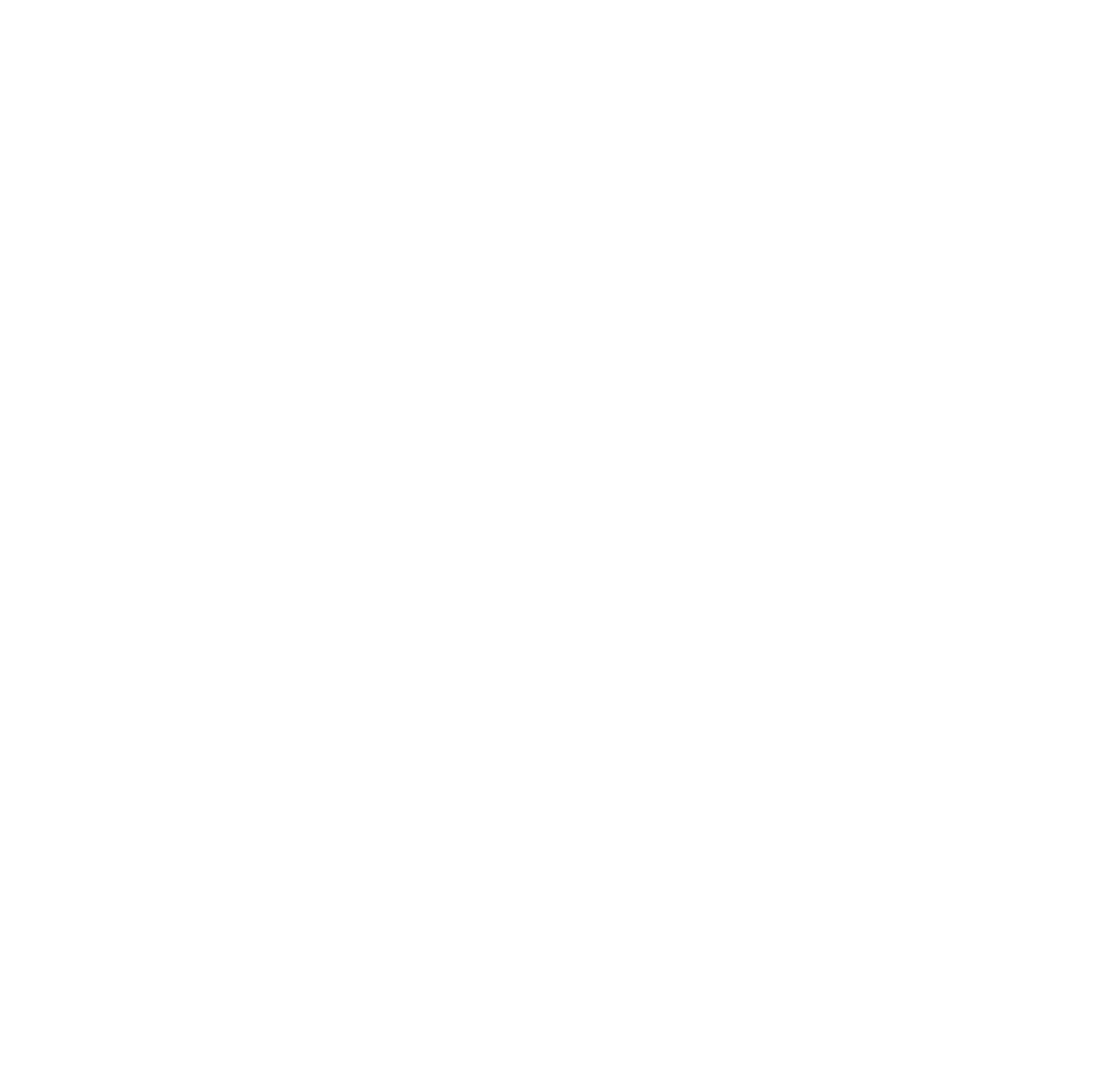

